ఠ

OPEN ACCESS

EDITADO POR

- Miguel Oliveira, Jr. (UFAL)

- René Almeida (UFS)

AVALIADO POR

- Rosangela Gabriel (UNISC)

- Lilian Hubner (PUC-RS)

DATAS

- Recebido: 27/12/2019

- Aceito: 29/01/2020

- Publicado: 09/07/2020

COMO CITAR

MORAIS, José (2020). Os caminhos da Literacia. Cadernos de Linguística, v. 1, n. 1, p. 01-14
ENSAIO TEÓRICO

\section{OS CAMINHOS DA LITERACIA}

\author{
José MORAIS iD
}

Unidade de Pesquisa em Neurociências Cognitivas - Universidade Livre de Bruxelas

RESUMO

São discutidos os conceitos, frequentemente utilizados no Brasil, de alfabetização e letramento, e criticadas, respetivamente, a sua insuficiência (posto que só a alfabetização não garante níveis hábeis de leitura e escrita) e imprecisão (no que respeita aos processos cognitivos utilizados). Defende-se a utilização de literacia, corrente em Portugal, a que correspondem literacy e littératie nos países de língua inglesa e francesa, e literacidad em alguns países de língua espanhola. Muito mais importante do que a harmonização da terminologia é fazer chegar aos meios educativos os conhecimentos científicos e neurocientíficos sobre o desenvolvimento e aquisição das capacidades cognitivas e de literacia, e sobre a enorme influência que têm sobre esse processo os fatores sociais, em particular a pobreza. Chama-se a atenção para o debate estéril que surgiv em torno de uma oposição mal colocada entre método fônico, baseado em evidências científicas, e a conscientização, proposta em tempos por Paulo Freire, da necessidade de desenvolver a literacia nos meios populares. Enfim, são analisadas as estatísticas do PISA relativamente ao Brasil, que põem em evidência não só o seu nível de literacia muito baixo como o fato de as capacidades de processamento racional e crítico de textos e da linguagem oral se reduzir a uma ínfima minoria da população, com o enorme perigo de que elas continuem limitadas a uma pequena franja correntemente chamada de "elite". Nota: este artigo teórico resume um curso que teve lugar no quadro de ABRALIN50. 


\section{ABSTRACT}

The concepts, often used in Brazil, of alphabetization and "letramento" are discussed, and their insufficiency (as alphabetization alone does not guarantee skilled levels of reading and writing) and vacuity (regarding the cognitive processes involved) are criticized. It is advocated the use of literacy, which is common in Portugal, and corresponds to literacy and littératie in English and French-speaking countries, and to literacidad in some Spanish-speaking countries. Much more important than harmonizing the terminology is to bring to the educational world the scientific and neuroscientific knowledge about the development and acquisition of cognitive and literacy capacities as well as about the enormous influence social factors, in particular poverty, have on this process. Attention is drawn to the sterile debate that opposes the phonic method, based on scientific evidence, and the campaign, headed 50 years ago by Paulo Freire, for developing literacy among the poorest. Finally, the PISA statistics relative to Brazil are analyzed. They highlight not only the Brazil's very low level of literacy but also the fact that the capacities of rational and critical processing of texts and oral language are reduced to a tiny minority, with the enormous danger that such capacities will remain limited to the small fringe currently called "elite". Note: this theoretical paper summarizes a course given in ABRALIN50.

PALAVRAS-CHAVE

Literacia; Método Fônico; Compreensão em Leitura; PISA; Pensamento Crítico.

KEYWORDS

Literacy; Phonics; Reading Comprehension; PISA; Critical Thinking. 


\section{INTRODUÇÃO}

No Brasil fala-se correntemente de alfabetização e de letramento.

Alfabetização é entendida como o ensino que faz com que o indivíduo, criança ou adulto, se torne capaz de ler e escrever no sistema alfabético, sem que, no entanto, sejam especificados os processos cognitivos envolvidos e a sua progressão, e, por conseguinte, o nível de habilidade atingido na leitura e na escrita.

Letramento é entendido como a "prática social" da leitura e da escrita, adquirida através do contato com a escrita e em contextos que põem em evidência questões e relações sociais, sem que, no entanto, se especifiquem aspectos como os processos cognitivos que supostamente conduzem a saber ler e escrever, se realmente se aprende a ler e escrever de maneira eficiente, quais e como são precisamente as questões e relações sociais subentendidas, que representações se desenvolvem dessas questões e relações, e em que medida estas representações ajudam a melhorar a inserção social dos indivíduos e as relações entre eles.

De fato, no Brasil fala-se muito de alfabetização e letramento. Como os resultados são péssimos, os totalmente analfabetos são quase $5 \%$ da população adulta e a maioria dos alfabetizados não vai além de uma leitura e escrita difíceis, com falhas graves que impedem um bom nível de compreensão e de alfabetização. Quanto ao letramento, este, à exceção de uma minoria, não conduz à formação de mentes capazes de desenvolver um pensamento racional, livre de preconceitos, e, por conseguinte, de análise e julgamento crítico aplicáveis às questões científicas e sociopolíticas.

Assim, parece que no Brasil - repita-se, com exceção da formação de minorias letradas - as bases imprescindíveis da educação que deveriam ser a alfabetização e o letramento estão faltando rotundamente, geração após geração, para $90 \%$ ou mesmo $95 \%$ da população escolar. Mais adiante, apresento números mais precisos em relação a níveis de capacidade no uso da leitura.

O que, sobretudo, está faltando hoje no Brasil, em matéria de educação, é entender a absoluta necessidade de fundá-la em uma concepção que tenha em conta:

(1) o conhecimento preciso do desenvolvimento das funções cognitivas até à idade adulta e da influência das experiências de vida e das aprendizagens ao longo desse desenvolvimento (tal conhecimento, necessariamente imperfeito, mas que tem progredido, é fornecido pela ciência, em particular pelas ciências e neurociências cognitivas, incluindo a ciência da linguagem);

(2) a vontade de generalizar a educação (uma educação consistente com aquele conhecimento) desde o nascimento da criança, isto é, de todas as crianças, quaisquer que 
sejam a sua classe social e as condições de vida de sua família, uma educação em que mesmo e sobretudo as crianças de meio pobre têm de receber, desde a creche, alimentação, cuidados de saúde, estimulação perceptiva e motora, assim como estimulação social e de linguagem, incluindo livros contendo imagens e caracteres escritos, que devem ser objeto de atenção conjunta da criança e do adulto; e

(3) a capacidade de aplicar, isto é, de pôr em prática, nessa educação generalizada, não só o conhecimento científico sobre o desenvolvimento cognitivo, como também a reflexão sobre os princípios sociais e morais.

De fato, se a alfabetização (para aprender a ler e escrever) e o letramento (para se sensibilizar à leitura e escrita como duas faces indispensáveis - sem menosprezar a fala e o discurso oral, os gestos e as experiências corporais - da comunicação entre humanos, necessariamente social) são ambos cruciais, o objetivo da educação a mais longo prazo e para toda a vida deve ser considerado em três direções:

- O desenvolvimento da capacidade estética (de sentir e criar beleza), que é social, mas também própria, exclusiva do indivíduo, e para seu prazer;

- O desenvolvimento da capacidade ética (de ter um comportamento moral), que é sentida intimamente, mas pressupõe a relação com os outros e o reconhecimento dos seus direitos e da sua liberdade e de que todos eles e todas elas são como nós, fundamentalmente iguais a nós; e

- O desenvolvimento da literacia.

\section{O CONCEITO E OS NÚMEROS DA LITERACIA}

O conceito de literacia, que à primeira vista não existe no Brasil - mas de algum modo existe, apesar de deturpado, ocultado, negado propositadamente, inclusive por letrados - tem de ser trazido para a ribalta, dado a conhecer, interrogado, examinado, compreendido na sua complexidade, e entendido como uma força material, força que nos transforma e transforma o mundo. 


\section{1. À PROCURA DE UMA PALAVRA}

O termo literacia e também o seu conceito, mas este em uma interpretação incompleta, são correntes em Portugal; na França, muito depois do Québec, da Suíça e até da Bélgica francófona, a littératie passou a ser reconhecida, até em textos oficiais. Nos países de língua hispânica (Espanha e América latina, sobretudo Colômbia, Uruguai e Argentina) tem havido, neste século, um surto do termo literacidad.

O uso de literacidad foi justificado, em uma revista de Florianópolis (Brasil), por dois autores $^{1}$ da Universidade Pompeu Fabra, de Barcelona, como sendo preferível a alfabetização e alfabetismo, e com razão, pelo fato de aqueles só contemplarem um sistema de escrita, o alfabeto. Embora vejam algum risco na escolha de literacía e literacidad, porque "suelen verse como préstamos del inglés literacy y pueden generar rechazo, además de parecer algo raros o infrecuentes a muchos docentes e investigadores" (CASSANY; CASTELLÀ, 2011, p. 356), não apresentam razões para a preferência por literacidad.

O argumento de proveniência do inglês é inaceitável. Não só porque a palavra literacy provém do latim através do francês (o que terá acontecido com cerca de $40 \%$ das palavras do inglês, sem que isso provoque urticária nos anglófonos), mas também porque o que está aqui aparente é a recusa de uma língua por esta ser a de potências imperialistas sem se ter em conta que é também a língua de povos que não podem ser considerados responsáveis pela política imperialistas desses Estados.

Quanto à recusa de literacía face a literacidad, o argumento aplica-se mal pois, como vimos, literacy foi adaptado a várias outras línguas e atualmente é de longe o termo mais utilizado nos estudos científicos e nos relatórios de instituições de muitos países.

Também vejo, na escolha de literacidad por aqueles autores e outros, a influência de um mau raciocínio, isto é, que "Entendemos mejor la literacidad si la concebimos como un conjunto de prácticas sociales" e "Las prácticas de literacidad están gestionadas u organizadas (patterned) por instituciones sociales y relaciones de poder" (p. 359).

Ora, a literacia é uma prática social, mas é também uma prática pessoal (do indivíduo para si mesmo no que ele tem de único, embora formado ou influenciado pela sociedade) e nem todas as práticas de literacia, longe disso, são geridas por relações de poder. Felizmente, ainda temos uma vida para além das relações de poder, e uma das razões para lutar contra as relações de poder é obter que, para cada ser humano, a literacia faça parte dessa vida.

Para todos os seres humanos, a aquisição da literacia, da condição de letrado, deve ser não um direito vazio, mas uma realidade. Atualmente, estamos muito longe disso, e obviamente porque os poderes estabelecidos, os governos, não organizam a educação com esse

1 D. Cassany e J.M. Castellà (2011). 
objetivo, mas para que se reproduzam as relações de poder entre minorias dominantes, caracterizadas em média por um nível de literacia elevado, e maiorias dominadas, nas quais há uma proporção muito maior de sub-letrados. ${ }^{2}$

\subsection{SER E FAZER LETRADOS}

Como definir o letrado? Podemos caracterizá-lo segundo condições de natureza cognitiva e enunciar uma condição necessária e outras que não são necessárias, mas são desejáveis para todos. Letrado é quem sabe ler e escrever as palavras (da ou das línguas que conhece) de maneira rápida, automática, não se dando sequer conta de como faz, de que processos mentais utiliza, isto é, sem ter de decodificá-las, na leitura, ou codificá-las, na escrita, de maneira progressiva, controlada conscientemente.

Quem sabe ler e escrever as palavras dessa maneira é quem já teve uma grande prática da leitura e da escrita de textos inúmeros e variados. Na escola, com variações devidas ao grau de complexidade do código ortográfico da língua, já há leitura e escrita automatizada da maioria das palavras de texto a partir do $3^{\circ}$ ano de escolaridade (no caso do português). ${ }^{3}$ Depois, com a continuação da prática desse tipo de leitura e escrita sobre outros conteúdos e estruturas sintáticas e léxicos mais sofisticados, a identificação e a produção das palavras escritas ou a escrever vai-se tornando cada vez mais rápida e exata. No fim do $6^{\circ}$ ano de escolaridade, quando o ensino é bom, a habilidade de leitura e escrita das palavras já quase não difere da do adulto. ${ }^{4}$

No curso intitulado Os caminhos da literacia, começamos por ver o que é exatamente a leitura hábil através de pesquisas sobre os movimentos oculares e o que é o processamento totalmente inconsciente realizado pelo nosso sistema cognitivo, o qual tem EM conta

2 Pode notar-se que, contrariamente aos autores que fazem parte das minorias dominantes ou simpatizam com elas, não utilizo o termo "elites" para designá-las. São os melhores em uma dada atividade, reconhecida como de alto valor para a sociedade, que fazem parte de elites. Marx, Einstein e Picasso fizeram parte de elites, respetivamente de filósofos, físicos e pintores. Porém, Hitler, Mussolini e Stalin, se bem que todos letrados, foram sobretudo ditadores violentos e criminosos, e ninguém, sem ironia e se não forem da mesma estirpe, reconhecerá uma elite de ditadores.

Do mesmo modo, não partilho a tendência atual de considerar que quem faz parte das minorias dominantes o deve ao fato de ter tido mais "mérito" do que quem não faz. Muita gente, senão toda, que faz parte das maiorias dominadas teria merecido usufruir - mas não foi o caso - de todas as oportunidades que aqueles que, beneficiando-se delas e aproveitando-as, vieram a ser reconhecidos como sendo os do "mérito". O "mérito" é um conceito criado para esconder a desigualdade de condição social e justificar o domínio da minoria sobre a maioria.

3 Plano Nacional de Leitura, Estudo Psicolinguístico (2010). "Estabelecimento de níveis de referência do desenvolvimento da leitura e da escrita do $1^{\circ}$ ao $6^{\circ}$ ano de escolaridade" (Janeiro de 2008 - Outubro de 2010), relatório de J. Morais, L. Araújo, I. Leite, C. Carvalho, S. Fernandes \& L. Querido.

4 Cf. Starr e Rayner (2001). Estes dados referem-se à língua inglesa, nos EUA. Dada a grande complexidade do código ortográfico do inglês, pode se esperar que a aproximação do padrão de movimentos do adulto pela criança se observe, no português, antes mesmo do $6 .^{\circ}$ ano, sob condição de um ensino eficiente. 
as características da estrutura da língua. Todo esse conhecimento foi obtido através de estudos experimentais de psicolinguística.

Outros estudos mostram como esses processos ocorrem no cérebro, em termos da localização das estruturas cerebrais ativadas (sobretudo a VWFA - sigla em inglês para "área da forma visual das palavras") e das conexões entre elas. Assim, com o aumento da habilidade de leitura, o funcionamento dessas áreas específicas do processamento das palavras escritas torna-se cada vez mais uma parte integrante do sistema de linguagem (o que tem em conta a sintaxe e a semântica) e torna-se cada vez mais independente das áreas que processam outras formas visuais, como rostos e imagens de objetos.

No curso, depois de examinarmos a leitura hábil, vimos o que os estudos científicos já mostraram sobre como melhor ensinar às crianças a leitura e a escrita, tomando para isso duas referências: a comportamental, quer dizer a melhoria do desempenho em termos de precisão e rapidez, com efeitos na compreensão e na produção de texto, que, pelo seu lado, são objeto de ensino e prática específicos; e a de ativação cerebral.

Como outros estudos mostram, antes do ensino na escola, a riqueza (ou pobreza) do meio linguístico da criança é um determinante importante do grau de sucesso das primeiras aprendizagens. A reprodução das minorias dominantes e das classes populares faz-se já então, e por isso mesmo o ensino e a sua qualidade são cruciais. Note-se, porém, que as minorias dominantes não incluem só letrados, e muito menos só letrados críticos (capazes de exame crítico da informação oral ou escrita), e que as classes populares podem incluir letrados e até letrados críticos.

Há quem hoje em dia, no Brasil, preconize que as crianças aprendam a ler e escrever em casa e não na escola pública, oferecendo uma bolsa (talvez de trinta dinheiros) sem dúvida movidos pelo interesse de poupar dinheiro para outros fins, isto é, desdenhando o fato de a grande maioria dos pais e mães não ter condições nem tempo, nem conhecimento e sequer nível de literacia para ensinar as crianças a ler e escrever. Isso é, pura e simplesmente, um crime, um infanticídio mental, educacional. O que é absolutamente necessário é elevar, mas em muito, o nível da escola pública, e, portanto, investir mais nela.

No que concerne à alfabetização, fase inicial no ensino da leitura e da escrita (visto que o nosso sistema de escrita é o alfabeto), os estudos científicos mostram que o método mais eficiente é o método fônico. Para além das diversas maneiras de pôr em prática este método, o primeiro passo é que se deve conduzir a criança a compreender o princípio alfabético, isto é, que os grafemas, letras ou pares de letras, correspondem a unidades fonológicas a que chamamos fonemas. Assim, o/p/, de "pa", não é um som, porque se quisermos pronunciá-lo dizemo-lo inevitavelmente com uma vogal, mesmo tênue, no fim, e se o juntarmos à vogal "a" não se obtém "ma", mas sim "pea".

Obviamente, há toda uma série de atividades, combinando leitura e escrita, que permitem fazer compreender o princípio alfabético e ajudam a operar mentalmente com os 
fonemas para os identificar e associar (ou os grafemas respetivos). E é muito importante que este trabalho seja sistemático, progressivo, indo dos fonemas mais acessíveis para os menos, sempre em relação com as letras, o que implica pôr em evidência os grafemas (em "cha", por exemplo, "ch" é o grafema inicial).

Acontece que o código ortográfico de quase todas as línguas contém não só grafemas complexos como regras contextuais (a leitura e a escrita de um fonema dependem do que o precede ou se the segue) e eventualmente irregularidades. Assim, quem alfabetiza deve conhecer bem o código ortográfico da sua língua e tê-lo em conta na organização temporal do ensino. Isto, não deve ser o professor ou professora a descobri-lo e, sim, deve aprender e exercitar isso durante a sua formação.

E ainda há quem pense que se deixe a alfabetização para os pais! E se os pais são analfabetos, quase analfabetos ou sub-letrados mal sabendo ler e não tendo livros em casa? Os mais letrados podem e, se for possível para eles, devem ajudar em casa, mas as escolas públicas precisam de bons especialistas do ensino da leitura e da escrita, e os governos devem pagar essa formação e assegurar-se da sua qualidade, o que implica um corpo de formadores com educação universitária na matéria e inspetores no terreno.

Tem havido más interpretações da aplicação do método fônico: que ele substitui o trabalho com a linguagem oral ou que ele toma todo o tempo e não permite atividades de compreensão de texto e produção escrita. A verdade é que o método fônico é para ser abandonado quando não for mais necessário.

Vimos acima que a decodificação (na leitura) e a codificação (na escrita) têm de ceder o seu lugar à leitura e à escrita hábeis, automatizadas. Como quando se aprende a andar de bicicleta ou a nadar. Só que aprender a ler e escrever requer mais tempo, mais exercício. Mas tem de haver essa passagem à automaticidade, e é responsabilidade de quem ensina assegurar-se de que irá acompanhando o aluno ou aluna até quando for ainda necessário.

Neste momento convém reforçar uma ideia: a de que o método fônico é apenas (o que já é muito) um método - o mais eficiente - de alfabetização. E que a sua utilização inteligente não diminui em nada a importância de, enquanto a criança não souber ler um número importante de palavras do texto (no mínimo 90\%), trabalhar com ela a compreensão da linguagem oral e da linguagem escrita, mas esta última lida pelo professor ou pela professora.

No Brasil, tem havido uma campanha de difamação relativa a um grande educador, Paulo Freire. Eu fiz parte do júri da tese de doutorado de Nilcéa Lemos Pelandré, em 1998, em que a autora relatou e comentou o que pode ter sido a entrevista que ela fez a Paulo Freire (falecido em maio de 1997) e que deve ter sido a última dele. ${ }^{5}$

5 Ler Pelandré (1998; 2002) 
Paulo Freire não pretendia ser um especialista dos métodos de ensino da leitura. O que ele sabia é que era possível ensinar a leitura a adultos analfabetos e que ela se ensinava melhor se eles o fizessem com palavras e textos que lhes falassem das suas vidas, dos seus problemas e das suas aspirações. Há palavras melhores do que "pobreza" e "trabalho" para começar a alfabetização, mas começando por elas esses analfabetos sabiam que lhes falavam do que era importante para eles.

A visita que lhes fez o presidente João Goulart também Ihes deu força. Quando este foi deposto violentamente pelo golpe militar e foram torturados e assassinados muitos jovens, em especial estudantes, aquela gente do povo que apenas estava aprendendo a ler e escrever foi perseguida, muitos tiveram de enterrar ou queimar os seus cadernos e alguns foram presos.

Voltando a Paulo Freire, ele é justamente reconhecido no mundo inteiro. ${ }^{6}$ E as críticas que the são feitas relativamente ao método de leitura são tão injustas como o seria criticar o grande pedagogo norte-americano John Dewey, um pouco anterior a Paulo Freire, por também não ter proposto que se utilizasse o método fônico.

Acontece que, como dito acima, Paulo Freire faleceu em 1997. Só em 1972 foi publicado um livro importante em que vários autores apresentaram e defenderam teoricamente, mas baseados em resultados experimentais, a utilização do método fônico para a aprendizagem da leitura e da escrita. E, depois disso, durante muitos anos ainda, continuou a haver um combate acirrado a essa proposta por outros psicolinguistas defensores do método global. ${ }^{7}$ Paulo Freire não era psicolinguista, não era cientista da cognição, era, como Dewey, um educador, homem de ideias que defendia uma ideologia certa.

\subsection{OS JOVENS BRASILEIROS, E O FUTURO DO PAÍS, FACE À LITERACIA}

Vejamos agora como têm estado em matéria de leitura, segundo o PISA, os adolescentes brasileiros escolarizados. Infelizmente, não há dados sobre a escrita, e seria tão importante que houvesse... O pavor que tiveram os poderosos através da História de que a escrita fosse uma arma contra eles parece permanecer ainda hoje. Nenhum país, nenhuma organização internacional, incluindo a ONU, assim como a OCDE nos seus sucessivos relatórios PISA, vai além da ideia de que a literacia é ser capaz de ler. E escrever?

Visto que não há informação sobre as capacidades de escrita (e nem sequer há dados sobre a leitura de palavras!), vejamos então como o PISA distingue entre níveis de compreensão em leitura, os únicos existentes relativamente à literacia em um número importante 
de países, cerca de 70, entre os quais faltam alguns países sobre os quais nos poderíamos interrogar, nomeadamente dois dos BRICS (Índia e África do Sul) e Cuba, conhecido por ter eliminado o analfabetismo depois da Revolução.

Indico abaixo os níveis de 1 a 6 e percentuais que lhes correspondem fazendo a média dos países da OCDE independentemente da população destes países.

A categoria mais baixa vai desde abaixo de 1c (compreensão literal de frases curtas e de vocabulário e sintaxe simples) até $7 a$ (se, sendo os índices explícitos, o tema principal e a intenção do autor são reconhecidos), incluindo, portanto, 1c e 1b. Nesse nível 1 e abaixo, a média é de $22.5 \%$. Há, portanto, quase um quarto de adolescentes escolarizados nos países considerados desenvolvidos que, na compreensão em leitura de texto, não estão em condições nem de desempenhar o seu papel de cidadãos, nem de ter um emprego minimamente intelectual ou que exija uma compreensão em leitura além do muito superficial.

No nível 2 (identificação da ideia principal e inferências básicas a partir de um texto de extensão moderada), a média é de $23.5 \%$, e não se pode dizer que se trata já de uma compreensão um pouco mais aprofundada. Assim, 46\% dos adolescentes dos países da OCDE são claramente sub-letrados.

O nível 3 já exige pôr informações em relação umas com as outras. Ele requer a extração do sentido literal de um ou mais textos na ausência de índices organizativos, o que implica a necessidade de integrar ou relacionar partes para identificar a ideia principal, fazer inferências e procurar informações.

Neste nível, em que certamente há compreensão em leitura, embora de textos que não sejam muito exigentes em termos de abstração ou reflexão, a média sobre os países da OCDE é de $26.5 \%$ dos alunos. É possível que parte desse pouco mais de um quarto dos adolescentes possa ser considerada letrada no sentido de leitor hábil, mas não temos informação sobre a maneira como eles processam as palavras.

Fazendo melhor do que isso, ou seja, nos níveis 4 e 5, só há, portanto, também 26.5\%.

O nível 4 requer a compreensão de passagens mais extensas e a interpretação de nuances de linguagem, em particular numa secção do texto tendo em conta outras ou o texto globalmente. Esses alunos podem também comparar perspectivas e fazer inferências a partir de várias fontes, comparar afirmações feitas em vários textos e verificar o grau de confiança em atribuí-las a uma fonte.

Se é razoável atribuir-lhes a condição de letrado (se não fossem leitores hábeis, não se vê como teriam tempo para processar essa quantidade de informação), por outro lado há ainda pouca evidência de capacidade de raciocínio crítico, portanto, de literacia crítica. Neste nível 4 a média dos países da OCDE é de 18.5\%.

Assim, apenas $8 \%$ atingem os níveis 5 e 6 , os de literacia de compreensão mais sofisticada e com uma boa capacidade crítica: pouco mais de $6 \%$ o nível 5 , e menos de $2 \%$ chegam ao nível 6. 
Mas, então, como aceitar que países desenvolvidos, depois de somadas as percentagens dos níveis 1 a 4 , venham a ser dirigidos por apenas $8 \%$ dos futuros letrados de muito bom ou excelente nível, isto é, pelos que têm uma capacidade de compreensão que inclui a abstração de conceitos e o raciocínio crítico? Obviamente, 8\% não são poucos, são milhões, e por serem tantos uma sociedade em que $8 \%$ comandam $92 \%$ é viável. Mas não é justo! Os meritocratas retorquem: é justo reconhecer o mérito. Mas como se chegou a tão grande disparidade de capacidade? Através de um sistema de formação à literacia viciado desde a infância.

Além dos países da OCDE, cerca de 40, participaram no inquérito cerca de 30 que não fazem parte dessa organização. Entre esses, pouco mais de 20 estão abaixo da média da OCDE, e os últimos 16, encabeçados pelo Brasil, não participam da OCDE.

Pouco acima da média da OCDE ficaram a Croácia e a Rússia (esta faz parte dos BRICS), e entre os seis primeiros contam-se quatro países asiáticos (em $1^{\circ}$ China - Pequim, Xangai, Jangsu e Zhejiang - membra dos BRIC, como o Brasil; em $2^{\circ}$ Macau; em $4^{\circ}$ Singapura, e em $6^{\circ}$ Hong Kong). A China destacou-se claramente dos outros países, com apenas 4.6\% de alunos abaixo do nível 2 (metade do melhor dos outros), e 21\% nos níveis 5 e 6 (ultrapassada, porém, por Singapura com $26 \%$, mas muito acima dos seguintes, com pouco menos de 15\%).

Como estava o Brasil em 2018? E qual tem sido a sua evolução? Comparemos 2018 a 2000 e a 2012.

Abaixo do nível 2, os adolescentes escolarizados brasileiros testados em 2000 (tinham nascido perto do fim da ditadura militar e começado a sua escolarização em 1991) eram 56\%, os testados em 2012 (escolarizados em 2003, tendo a primeira presidência de Lula começado em 1. de Janeiro daquele ano) foram 52\%, e em 2018 (escolarizados em 2011, ano em que Lula terminou a sua presidência e foi substituído por Dilma) desceram para $50 \%$.

No conjunto, o período em que o PT esteve no poder promoveu uma diminuição de 6\% dos muito maus leitores, o que é um indicativo positivo, mas muito mais deveria e poderia ter sido feito se a alfabetização e o ensino da literacia tivessem sido baseados nos conhecimentos científicos e nas recomendações destes (Cf. RAYNER et al., 2001).

Quanto aos muito bons leitores brasileiros (níveis 5 e 6), eles não chegavam a $0.5 \%$ (dito de maneira mais impressionante, menos de 1 em 200 no ano 2000. Esse número foi multiplicado por mais de 4 em 2012, visto que os muitos bons leitores passaram a 2\%, mas infelizmente em 2018 continuaram a ser apenas $2 \%$. As mudanças, descida nos péssimos e subida nos muito bons, aconteceram durante os mandatos de Lula, e este progresso estancou ou inverteu-se nos anos seguintes.

Não é fácil dar conta da variedade de fatores potencialmente responsáveis pela tendência à reversão: crise financeira de 2008, instabilidade política durante os mandatos de 
Dilma e retomada de políticas neoliberais, e enfim entrega (recente, mas com efeitos imediatos de desorganização) da política da educação a ideologias e práticas ultrarreacionárias em um contexto social e moral totalmente deletério (para não dizer insalubre ou, ainda mais apropriado, venenoso). Todos esses acontecimentos tiveram provavelmente influência, e é permitido recear resultados ainda piores daqui a três anos.

Fica, por enquanto, para cruel meditação, o contraste entre estes dois países dos BRICS, isto é, Brasil e China: leitores de alto nível, respetivamente $2 \%$ e 21\%; maus leitores, $50 \%$ e menos de $10 \%$. Atualmente, na razão aproximativa de $1: 10$ em ambos os extremos. 0 futuro próximo desta "terra abençoada por Deus" afigura-se ainda mais inquietante. É impossível saber onde está a chave de um esboço de reviravolta: em uma parte da elite mais iluminada, ou nas mãos dos dominados de pouca literacia, porém de inteligência e coragem suficientes? Ou em ambas as partes caso se dêem as mãos?

\section{DUAS COMPONENTES ESSENCIAIS DA LITERACIA: AS CAPACIDADES DE CRÍTICA E DE CRIAÇÃO}

As capacidades de crítica e de criação são, ambas e conjuntamente, cruciais para as mudanças culturais nas sociedades humanas. Estas mudanças constituem, na maioria dos casos, o que chamamos avanços ou progressos, concretizados em melhorias e inovações. Essas capacidades já existiam antes da invenção da escrita (obviamente, esta resulta justamente do exercício delas) e até mesmo da linguagem falada.

A capacidade de criação tornou possível o aparecimento e o desenvolvimento, desde há cerca de dois milhões e meio de anos, da tecnologia lítica, isto é, da manufatura de instrumentos de pedra pelos hominídeos, nossos antepassados. A capacidade de crítica (de si mesmo ou dos outros) terá sido necessária desde logo para serem realizadas mudanças, em princípio aperfeiçoamentos, a fim de, nomeadamente tornarem a caça mais eficiente.

Certas mudanças terão sido mesmo revolucionárias, como aconteceu, há cerca de um milhão de anos, na passagem das pedras que apresentavam uma aresta cortante produzida por um percutor, a outras, bifaciais, em que as duas faces da pedra iam sendo desgastadas e retocadas para se obterem bordas cortantes. A criação de instrumentos de metal, essa, ocorreu, antes da invenção da escrita. Obviamente, a preparação de todos esses instrumentos, de pedra e de metal, exigiu aprendizagem, isto é, mestres e aprendizes.

Havia então uma interação entre as mãos e o pensamento que primeiro foi mediada por gestos e vocalizações relativamente simples e, mais tarde, pela linguagem falada proposicional. Até que a invenção da escrita fixou a linguagem em todos os suportes possíveis, desde a pedra e os cacos de argila até o papel e, hoje, a transcrição digital em 
computador. Essa permanência da linguagem e, portanto, do pensamento revolucionou as capacidades cognitivas.

Avaliar os efeitos de uma revolução, qualquer que ela seja, implica comparar o antes e o depois, mas não teria sentido comparar, por um lado, as revoluções tecnológicas e no pensamento antes e depois do desenvolvimento da linguagem, com, por outro lado, o antes e o depois da invenção da escrita e das suas diferentes formas. De qualquer modo, essas revoluções são formas radicais de crítica e criação que, elas mesmas, revolucionam as capacidades que as tornaram possíveis.

Essas duas capacidades não são independentes. Capacidade de crítica implica superação, criação de ideias, e estas requerem exame crítico, sobretudo quando o "meio", isto é, o material com que se trabalha, é a linguagem, falada ou escrita.

Historicamente, desde a invenção da escrita, a primeira grande manifestação de pensamento crítico e criativo foi a ciência, ou seja, a literacia científica. A ciência progride através da aplicação impiedosa da crítica que, para não ficar estéril, para não ser apenas questionamento, necessariamente se prolonga na criação de novas hipóteses e de paradigmas de verificação.

A linguagem, ela mesma, e a linguística, que como ciência a examina, são objeto de crítica, e esta crítica engendra um processo revolucionário que se resolve pela criação ou pela transformação das ideias anteriores sobre a linguagem, e, se isto é válido para todas as ciências, a linguística deveria ser exemplar no respeito desta dinâmica (deveria: o que implica que muitas vezes não o é - a resistência à crítica, a luta para não se deixar corrigir, transfigurar, pode ser desesperada). O mesmo se pode dizer da ciência cognitiva, em particular da que estuda as capacidades humanas, e de todas as outras ciências do humano, individual ou social.

\section{NOTA APRESENTADA NO PRIMEIRO DIA DO CURSO, EM 2 DE MAIO DE 2019}

Antes de explicar o que é literacia e por que não pode ser reduzida a alfabetização, quero prestar homenagem a um letrado brasileiro, grande homem de teatro, que faleceu há exatamente 10 anos, Augusto Boal. Ele fundou o Teatro de Arena de São Paulo em 1956 e até 1964 encenou peças clássicas assim como teatro popular e foi o inventor do spectactor, depois retomado na televisão norte-americana. A partir do golpe militar de 1964 não pôde trabalhar, foi preso na rua em 1971 por ter escrito "O teatro do oprimido", foi torturado e obrigado ao exílio na Argentina e de lá ele se auto-exilou indo para Paris onde criou em 1979 o Centro do Teatro do Oprimido e organizou festivais de teatro. No fim da ditadura, em 1986, voltou para o Rio de Janeiro. Escreveu outros livros, foi sobretudo um inovador em 
matéria de teatro, inclusivamente uma forma de teatro que chamou terapêutico, chamado "o polícia na cabeça". O seu teatro em Paris chama-se hoje "Teatro do Oprimido - Augusto Boal". Augusto Boal é conhecido mundialmente e tem uma notícia sobre ele na Wikipédia. Como leitura, aconselho o livro "A estética do Oprimido", acessível pela Internet: <theaestheticsoftheoppressed.pdf> (em inglês).

De fato, Augusto Boal, grande homem de teatro, letrado crítico e criativo que, em nível internacional revolucionou essa arte pelas suas encenações e pelos seus livros e que, pelas suas posições e coragem políticas denunciou a ditadura à sociedade brasileira e ao mundo, é um exemplo, vivo para sempre, do que deveria ser nos nossos tempos, para todos nós, humanos, a literacia: uma dimensão de nós mesmos, que adquirimos em criança, que nos define para sempre, através da qual percebemos a nossa identidade.

\section{AGRADECIMENTOS}

O autor agradece a Régine Kolinsky, a sua leitura crítica da primeira versão deste artigo.

\section{REFERÊNCIAS}

CASSANY, D.; CASTELLÀ, J. M “Aproximación a la literacidad crítica”. Perspectiva, v. 28, n. 2, p. 353-374, 2011.

RAYNER, K. et al. "How Psychological Science Informs the Teaching of Reading". Psychological science in the public interest, v. 2, n. 2, p. 31-74, 2001.

MORAIS, J. A arte de ler. São Paulo: UNESP, 1996.

STARR, M.S.; RAYNER, K. "Eye Movements During Reading: Some Current Controversies". Trends In Cognitive Sciences, v. 5, n. 4, p 156-163, 2001.

PELANDRÉ, N.L. Efeitos a longo prazo do Método de Alfabetização. Tese (Doutorado em Letras/Linguística) Curso de Pós-Graduação Letras/Linguística, Universidade Federal de Santa Catarina, Florianópolis, 1998.

PELANDRÉ, N.L. Ensinar e aprender com Paulo Freire: 40 horas, 40 anos depois. São Paulo: Cortez, 2002. 